\title{
Epistemologia na Ciência da Informação: a visão de Mortimer Taube
}

\author{
Keitty Rodrigues Vieira* \\ Cezar Karpinski**
}

Artículo recibido:

11 de marzo de 2021

Artículo aceptado:

18 de mayo de 2021

Artículo de revisión

\section{Resumo}

Diante da discussão epistemológica da área, este artigo, resultado de uma tese, visa discutir as perspectivas epistemológicas identificadas na produção científica de Mortimer Taube. Portanto, este artigo identifica especificamente as abordagens epistemológicas que serviram de base para a produção científica de Taube. Metodologicamente, o estudo caracteriza-se por ser qualitativo, exploratório, bibliográfico e documental, sem delimitação cronológica, e baseado na hermenêutica para a interpretação e redação dos resultados. As fontes utilizadas foram selecionadas de acordo com

* Universidade Federal de Santa Catarina, Departamento de Ciência da Informação, Programa de Pós-Graduação em Ciência da Informação, Brasil

keitty_rodriguesvieira@hotmail.com

** Universidade Federal de Santa Catarina, Departamento de Ciência da Informação, Brasil cezark@hotmail.com

INVESTIGACIÓN BIBLIOTECOLÓGICA, vol. 35, núm. 88, julio/septiembre, 2021, México, ISSN: 2448-8321 pp. 185-206 
sua especificidade e devido à participação da Taube com tais instituições, são elas: Association for Information Science and Technology, Duke University, Library of Congress, Columbia University, Digital Journal Storage Library, NASA Library, Biblioteca Nacional, University of Chicago Press Journal and the Library Quarterly. Dos 264 documentos recuperados, 124 foram lidos e analisados e constituem o corpus deste artigo. Os resultados mostram que as abordagens epistemológicas que permeiam a obra de Taube são o Positivismo Lógico e a Filosofia Analítica, e que sua posição epistemológica pode ser identificada pela abordagem da Epistemologia Crítica.

Palavras-chave: Epistemologia da Ciência da Informação; Escolas e Correntes Filosóficas; Mortimer Taube

Epistemología en la ciencia de la información: la visión de Mortimer Taube

Keitty Rodrigues Vieira y Cezar Karpinski

\section{RESUMEN}

Frente a la discusión epistemológica del área, este artículo tiene como objetivo discutir los enfoques epistemológicos identificados en la producción científica de Mortimer Taube. Por lo tanto, este artículo identifica específicamente los enfoques epistemológicos que sirvieron de base para la producción científica de Taube y problematiza los constructos teóricos de este autor. Metodológicamente, el estudio se caracteriza por ser cualitativo, exploratorio, bibliográfico y documental, sin delimitación cronológica, y basado en la hermenéutica para la interpretación y redacción de los resultados. Las fuentes utilizadas fueron seleccionadas de acuerdo con su especificidad y debido a la participación de Taube con tales instituciones: Association for Information Science and Technology, Duke University, Library of Congress, Columbia University, Digital Journal Storage Library, NASA Library, Biblioteca Nacional, University of Chicago Press Journal y Library Quarterly. De los 264 documentos recuperados, 124 fueron leídos y analizados y conforman el corpus de este artículo. Los resultados muestran que los enfoques epistemológicos que impregnan la obra de Taube son 
el Positivismo Lógico y la Filosofía Analítica, y que su posición epistemológica puede ser identificada por el enfoque de Epistemología Crítica.

Palabras clave: Epistemología de la Ciencia de la Información; Escuelas y Corrientes Filosóficas; Mortimer Taube

Epistemology in information science: Mortimer Taube's vision

Keitty Rodrigues Vieira and Cezar Karpinski

\section{Abstract}

Faced with the epistemological discussion of the area, this article aims to discuss the epistemological approaches identified in Mortimer Taube's scientific production. Therefore, this article specifically identifies such epistemological approaches that served as the basis for Taube's scientific production and questions the theoretical constructs of this author. Methodologically, the study is characterized as qualitative, exploratory, bibliographic and documentary, without a chronological delimitation, and based on hermeneutics for the interpretation and writing of the results. The sources used were selected according to their specificity and because of Taube's involvement with such institutions; they are: Association for Information Science and Technology, Duke University, Library of Congress, Columbia University, Digital Journal Storage Library, NASA Library, Biblioteca Nacional, University of Chicago Press Journal and the Library Quarterly. Of the 264 documents recovered, 124 were read and analyzed, and make up the corpus of this article. The results show that the epistemological approaches that permeate Taube's works are Logical Positivism and Analytical Philosophy, and that their epistemological position can be identified by the Critical Epistemology approach.

Keywords: Epistemology of Information Science; Schools and Philosophical Currents; Mortimer Taube 
$\mathrm{O}$ s estudos sobre epistemologia na Ciência da Informação são habituais na literatura científica da área, a exemplo de publicações recentes como as de Silva e Freire (2020) com o livro Epistemologia e bistoriografia na Ciência da Informação, a obra Escola de Chicago e Ciência da Informação: influências, aproximações e contribuições de Vieira e Karpinski (2020) e Saldanha (2020) com o livro Ciência da Informação: crítica epistemológica e historiográfica. Com relação aos artigos científicos, é possível destacar algumas produções também recentes que discutem a epistemologia na Ciência da Informação e a aproximam de temas transversais, como a história, a competência em informação, estudos informacionais, o pensamento decolonial e as discussões da arquivologia. Como exemplo, é possível citar Vieira e Karpinski (2019), Lucca e Vitorino (2020), Martínez-Ávila e Zandonade (2020), Righetto e Karpinski (2021), e Ávila, Matos e Rendón-Rojas (2021).

De acordo com Japiassu (1977), a epistemologia é um estudo reflexivo do saber e de seus produtos intelectuais. Especificamente, a Ciência da Informação tem adotado o conceito de epistemologia como uma área que, a partir de estruturas teóricas, busca a compreensão dos objetos de estudo daquele determinado campo de conhecimento (Rendón-Rojas, 2008).

Hjørland (2002) entende os estudos epistemológicos como uma forma de analisar determinado domínio do conhecimento o que, no caso da Ciência da Informação, forma uma base interdisciplinar que se debruça sobre as teorias em torno da organização do conhecimento. Além disso, Francelin (2018) reforça a pluralidade epistemológica da Ciência da informação dado a natureza complexa do pensamento que é percebida na análise da produção científica feita pelo autor.

A interdisciplinaridade também é considerada por Aguiar (2014) como ponto de reflexão epistemológica na área. Para a autora que identifica tríades conceituais na Ciência da Informação, a epistemologia é discutida a partir da integração entre Biblioteconomia, Arquivologia e Museologia, o que permite debater a área sobre perspectivas diferentes.

Sendo assim, este artigo entende a informação, objeto de estudo da Ciência da Informação, como um objeto interdisciplinar, permeado por concepções teórico-epistemológicas provenientes de diversas disciplinas. Portanto, esta pesquisa se debruça na discussão epistemológica da Ciência da Informação a partir do recorte estadunidense dos profissionais atuantes entre as décadas de 1940 e 1960, período que consiste na institucionalização da área.

Com isso, ao pesquisar sobre a história da Ciência da Informação e suas relações com a Biblioteconomia estadunidense, se identifica o nome de 
Mortimer Taube como um personagem que atua nesta perspectiva epistemológica e interdisciplinar. Taube é um nome pouco abordado na literatura científica da área mesmo que suas obras apontem para a existência de lacunas na discussão epistemológica da Ciência da Informação. Embora seu nome seja, comumente, vinculado à temática da indexação, seu vínculo com a tecnologia e os computadores tanto na Biblioteconomia quanto no que hoje se considera a Ciência da Informação o fazem refletir sobre até que ponto a Informática poderia substituir as capacidades humanas de trabalho e de pensamento. Essas reflexões teóricas o fazem se questionar sobre a área e a posição assumida pelos profissionais da informação e suas instituições.

Para Fonseca (2007: 6), Mortimer Taube "fundava em Washington a empresa Documentation Incorporated, vitoriosa até sua morte, em 1965, a julgar pelo número de importância de seus associados - mais de 500 - dois dos quais a National Aeronautics and Space Administration (NASA) e a United States Air Force (USAF)".

Sua formação em Filosofia na University of Chicago por volta dos anos de 1930, e seu posicionamento matemático e lógico apontam uma faceta desconhecida de Taube: seu posicionamento epistemológico. Afinal, a University of Chicago nas décadas de 1920 e 1930 foi berço do movimento intelectual pautado no Pragmatismo, ainda que Taube não se aproxime desta vertente. Outras perspectivas presentes na Ciência da Informação, como o Positivismo Lógico, a Filosofia Analítica e a Filosofia da Linguagem, são perspectivas que aparecem em, pelo menos, uma das obras de Taube (1967), o que pode ser um indício de que o pesquisador assumia essas abordagens epistemológicas.

Além disso, caracterizando sua história na Ciência da Informação, Taube era um filósofo e bibliotecário, que tinha como tema de pesquisa a tradução mecânica, unindo teorias da linguística e informática, com sua expertise sobre Organização e Representação do Conhecimento e da Informação, em especial ao que se refere à indexação.

Diante disso, este artigo objetiva discutir as abordagens epistemológicas identificadas na produção científica de Mortimer Taube. Por isso, o artigo problematiza os construtos teóricos de Taube na medida em que o identifica como um bibliotecário e cientista da informação.

Os resultados mostram que Mortimer Taube toma por base as perspectivas do Positivismo Lógico e da Filosofia Analítica para discutir questões teóricas e epistemológicas da área. Neste sentido, o autor aprofunda temas como a cientificidade da Biblioteconomia, a relação entre as práticas da documentação e a Recuperação da Informação, e a própria informação como um objeto complexo que deve ser alvo de estudos de diferentes áreas e de forma colaborativa. 
Por isso, entende-se que a pesquisa por autores "marginais" da história da Biblioteconomia e Ciência da Informação, a exemplo de Mortimer Taube, enriquece os estudos históricos e epistemológicos e apresenta novas possibilidades de interpretação e compreensão do processo histórico da Ciência da Informação. Casos como o apresentado neste artigo contribuem para o debate interdisciplinar da área, uma vez que destacam contribuições de outras perspectivas que possuem interconexões com a Ciência da Informação.

\section{Metodologia}

Este artigo é um estudo qualitativo, exploratório, do tipo bibliográfico e documental, sem delimitação cronológica nos termos de Lira (2014) e Minayo, Deslandes e Gomes (2013). Além disso, trata de uma reflexão teórica que, nas palavras de Sales (2012: 17), possui como "pressuposto metodológico, não técnicas procedimentais como as coerentemente demandadas por pesquisas de caráter mais aplicadas mas, sim, um método que sirva a uma abordagem”.

Neste caso, a análise dos dados se dá por meio de interpretação, considerada por Azevedo (2004) como característica principal da prática hermenêutica. Para este autor, "a prática da hermenêutica pressupõe um esforço sistemático, metódico, deliberado no sentido de conhecer uma determinada realidade concebendo-a de uma maneira particular. Trata-se, portanto, de uma postura e de uma maneira de se colocar diante dos acontecimentos" (Azevedo, 2004: 130).

A coleta dos dados data do segundo semestre de 2020 e, em função da especificidade do tema, as fontes consultadas foram escolhidas a partir de informações sobre a trajetória profissional de Mortimer Taube. São elas: Association for Information Science and Technology, Duke University, Library of Congress, Columbia University, Biblioteca Digital Journal Storage, Biblioteca da NASA, Biblioteca Nacional, University of Chicago Press Journal e o periódico Library Quarterly. Dos 264 documentos recuperados, 124 foram lidos e analisados e compõem o corpus de análise deste estudo.

A discussão toma por base o argumento de Cupani (2017) sobre epistemologia, a fim de identificar se a obra de Taube se aproxima da reflexão filosófica ou da reflexão epistemológica. No caso desta última, o artigo considera os conceitos e classificações de Japiassu (1977) para identificação das possíveis vertentes epistemológicas presentes em Taube. 


\section{ApresentaÇÃo E ANÁlise dos Resultados}

A tipologia de fontes de informação é diversificada contando com artigos, resenhas, livros, capítulos de livros, relatórios técnicos, cartas ou comentários à periódicos e material de divulgação. Destes, os artigos sobre Taube, Sistema Unitermo ou acerca da empresa Documentation Incorporated foram os mais recuperados uma vez que somam 51 documentos. Neste montante, os artigos de Taube somam 25, as cartas ou comentários à editores resultam num montante de 10 documentos, enquanto as resenhas de autoria de Taube somam nove textos e as resenhas sobre publicações de Taube, com autorias diversificadas, foram sete.

Do montante de 124 documentos, 52 são de autoria de Taube ou foram publicados sob responsabilidade da Documentation Incorporated. Os metadados destes materiais indicam que a publicação mais antiga data de 1936 e, a mais atual, é de 1965. Os documentos que abordam sobre Taube, Sistema Unitermo ou a empresa Documentation Incorporated resultam num total de 72, sendo o primeiro datado de 1937 e o último de 2020.

A relação de Mortimer Taube com as questões epistemológicas é algo que transpassa sua trajetória acadêmica e profissional por meio de sua contribuição bibliográfica, especialmente para a área da Biblioteconomia e Ciência da Informação. Ademais, o fato de Taube pertencer tanto à Filosofia quanto à Biblioteconomia, além de atuar com a documentação, o faz utilizar conceitos e construtos teóricos de ambas as áreas para fundamentar sua produção.

Ao analisar o trabalho de Taube se percebe que o mesmo não acredita nem no positivismo clássico, que despreza as questões empíricas, nem no empirismo tradicional, que está vinculado diretamente à experiência. A discussão de Taube se dá de forma moderada, sem seguir os extremismos das duas correntes filosóficas, e, assim, pode-se dizer que seu posicionamento vai ao encontro do Positivismo Lógico, ou empirismo lógico.

Esta corrente é de interesse dos pesquisadores da filosofia da ciência que a consideram como uma disciplina distinta, que se utiliza de ferramentas da lógica moderna com o foco na discussão científica e com o apoio dos lógicos e matemáticos do século XIX e XX, conforme explicação de Cunha (2012). Ademais, o Positivismo Lógico considera outra questão já comentada por Taube, a questão da linguagem.

Neste sentido, Abbagnano (2012) explica que a redução da filosofia à linguagem pode ser distinguida em duas tendências de pesquisa: a primeira que trata da linguagem científica e, a segunda, da linguagem comum. Dutra (2010) que comenta sobre a influência de Russell e Wittgenstein na corrente do Positivismo Lógico, dá destaque à tradução dos enunciados. O que, 
por unir a lógica, a matemática e a linguagem, direciona a discussão para a Filosofia Analítica do século XX. Aqui, há três palavras-chave para a compreensão do debate da Filosofia Analítica na área da Biblioteconomia e Ciência da informação. São elas: enunciado; lógica e; linguagem.

A definição de 'enunciado' é encontrada em Abbagnano (2012), Cunha e Cavalcanti (2008) e em Wagner Jr. (1960), representando as perspectivas da Filosofia, Biblioteconomia e Documentação. Trata, portanto, de uma expressão linguística que é verdadeira ou falsa, e que possui sentido completo (Abbagnano, 2012).

O autor explica que, na lógica medieval, os termos 'proposição', 'questão', ‘conclusão' e 'enunciado' eram considerados praticamente idênticos, e o que distingue 'enunciado' dos demais é que, neste caso, a enunciação é apresentada sem necessitar de outras condições, como a premissa, o argumento ou a dúvida. Abbagnano (2012) ainda complementa que esta definição é mantida pela lógica moderna, por autores como Carnap e Quine.

Já o dicionário de Biblioteconomia e Arquivologia identifica 'enunciado' como uma expressão de qualquer linguagem, uma proposição que tenha sentido. E ainda especifica o 'enunciado de busca' que são as combinações de termos utilizados na recuperação da informação (Cunha e Cavalcanti, 2008), também conhecidas por strings.

Percebe-se que a definição de enunciado para a área da Biblioteconomia possui um significado prático, voltado ao fazer profissional o que, de certa forma, é uma característica da área, na perspectiva de Taube. Isto porque, sua compreensão de que a Biblioteconomia é um serviço (Slamecka e Taube, 1964) o coloca numa posição em que suas concepções sejam viáveis em termos aplicados. Ademais, é visto que a produção de Taube é fluída pois ele passa por momentos teóricos, momentos de discussão epistemológica e momentos voltados à aplicabilidade de seus estudos em projetos específicos.

Analisadas a partir da lógica booleana (Taube e Wachtel, 1953; Documentation Incorporated, 1953), as 'unidades de informação' que originam o Unitermo se assemelham a ideia de enunciado apresentada por Abbagnano (2012). Isto porque estes termos, sejam de sentidos completos ou não, são enunciados que permitem a operacionalização da busca, quando aplicados ao contexto biblioteconômico, seja em ambientes manuais ou automatizados.

Abbagnano (2012: 722) define a lógica como "a disciplina que privilegia o estudo de conjuntos coerentes de enunciados". Coerentes no sentido das situações onde há a possibilidade que estes enunciados sejam verdadeiros. $\mathrm{O}$ autor, ao contextualizar teoricamente os estudos em lógica, afirma que, no século XVII, Gottfried Wilhelm Leibniz (1646-1716) propõe a matematização da lógica por meio da aproximação com a álgebra. Todavia, Abbagnano afirma 
que o projeto de Leibiniz só começa a se concretizar com George Boole (18151864), a partir de 1847 quando, "munido dos resultados atingidos pela álgebra do seu tempo, muda o foco da atenção: das operações lógicas para as próprias operações" (Abbagnano, 2012: 724).

No campo das definições que importam à Biblioteconomia, a Lógica é "a ciência das condições necessárias e suficientes para se chegar ao conhecimento da verdade" (Cunha e Cavalcanti, 2008: 235). A partir disso, o verbete é dividido em tipologias da lógica, como a lógica do termo ponderado, lógica difusa e lógica booleana, que o dicionário prefere remeter à álgebra booleana.

Definido como um sistema de notação que analisa e descreve a proposição como verdadeira ou falsa, por meio do ponto de vista lógico, a álgebra booleana é identificada na Biblioteconomia a partir dos operadores booleanos. Dessa forma, pode-se dizer que a lógica atua vinculada à recuperação da informação. Neste caso, tratam de operações lógicas utilizadas como estratégias de busca, envolvendo os operadores 'E', 'OU' e 'NÃO' (Cunha e Cavalcanti, 2008).

$\mathrm{Na}$ Documentação, a lógica é um conjunto de leis e meios que são capazes de determinar a validade de determinado raciocínio, caracterizada como uma estrutura racional ou normativa (Wagner Jr., 1960), uma definição bem próxima de Abbagnano (2012). Afinal, o conceito gira em torno da validade e coerência dos enunciados, sem se aproximar da aplicabilidade dos operadores booleanos na área.

Nos escritos sobre o Unitermo, Taube comenta diversas vezes sobre o uso da lógica booleana para a construção do sistema (Taube e Thompson, 1951, citado por Gull, 1987; Taube e Wachtel, 1953; Documentation Incorporated, 1953). E, assim como no caso dos enunciados, publica os resultados da discussão filosófica nos periódicos da área de Filosofia, e a parte operacional direciona à Biblioteconomia, retroalimentando teoria e prática, debates específicos da acadêmica com experiências de seu trabalho técnico.

A linguagem é outro ponto central neste assunto. Na Filosofia, Abbagnano (2012) esclarece que o problema da intersubjetividade dos signos e seu fundamento é a grande questão da discussão sobre a linguagem, que é objeto de interesse especialmente da filosofia contemporânea.

$\mathrm{Na}$ Biblioteconomia a linguagem é definida como um meio de expressar as ideias, um "conjunto de convenções e regras sobre como transmitir informações entre pessoas e máquinas” (Cunha e Cavalcanti, 2008: 225). Ou seja, uma perspectiva fisicista da troca de informação entre emissor e receptor nos termos de Shannon e Weaver (1964).

A questão da linguagem é discutida por Taube sob o prisma da tradução da linguagem natural para uma linguagem compreendida por máquinas, uma abordagem muito semelhante com a discussão da documentação sobre 
o tema. Isto porque, na proposta conceitual de Wagner Jr. (1960), a linguagem não aparece de forma isolada como, por exemplo, o verbete 'machine language', onde a linguagem de máquina é definida como um método de codificação, semelhante ao discurso de Taube.

Jones e Taube argumentam que não é possível transpor a experiência humana às máquinas e que, por este motivo, é inviável que a máquina possa perceber definições e classes (Jones e Taube, 1961). Deixando esta ação, portanto, exclusiva do ser humano que deve fazer as inserções nos sistemas para que, de forma mecanizada, a máquina reconheça aquele conjunto de caracteres. Com isso, percebe-se outro indício de que Taube entende a linguagem como algo que se desenvolve no contexto humano e que, apenas, é reproduzido pela máquina, conforme as instruções humanas. É por isso que não se encontra momentos onde Taube defenda uma linguagem de máquina porque, para ele, esta linguagem é um código e não uma construção da língua.

Outra palavra que aparece de forma recorrente nos escritos de Taube é o termo 'ciência'. A ciência, na concepção moderna da Filosofia, é um "conhecimento que inclua, em qualquer forma ou medida, uma garantia da sua própria validade" (Abbagnano, 2012: 157). Isto porque, na visão tradicional, a validade do conhecimento científico é de caráter absoluto, sendo que não há essa pretensão na discussão contemporânea.

$\mathrm{Na}$ Biblioteconomia, ciência é "conhecimento de fatos ou princípios, adquiridos por meio do estudo sistemático. Ramo especial de um conhecimento, organizado sistematicamente" (Cunha e Cavalcanti, 2008: 81). Portanto, uma definição de perspectiva positivista onde há um sujeito, que analisa um determinado objeto a partir de um método e que, por fim, alcança um determinado resultado.

Neste sentido se percebe que Taube se aproxima da definição da ciência sob a perspectiva filosófica construtivista nos termos de Abbagnano (2012). Para o autor, a perspectiva construtivista possui, em geral, como antecedentes teóricos o positivismo lógico de Carnap e a filosofia matemática, presentes em Taube.

Em seus escritos, Taube acredita que a ciência não se destina somente à cientistas, mas às pessoas interessadas no assunto. Para ele, "Poucos reparam que a ciência é a uma forma de empreendimento intelectual que não dispõe nem de executantes nem de críticos informados. [...] os cientistas insistem em que qualquer análise crítica de seus trabalhos constitui censura ou incapacidade de apreciar a necessidade de pesquisas básicas (têrmo que às vêzes pode ser interpretado como ‘triviais' ou 'inúteis')” (Taube, 1967: 114-115).

E, por isso, a crítica à ciência não é algo bem visto pela sociedade da época, algo que Taube tenta romper com a publicação da obra "Os computadores: o 
mito das máquinas pensantes”. Já na abertura do livro, o autor afirma que a proposta é tentar aproximar a crítica científica da crítica da literatura, da música e da arte, que entendem a crítica como um empreendimento científico, e não como uma censura ao seu trabalho. O que, em linhas gerais, é uma crítica ao processo de 'endeusamento' da ciência que a coloca como uma verdade dogmática.

\section{Discussão}

Percebe-se que Taube fundamenta sua discussão em importantes nomes da Filosofia. São eles: Alfred North Whitehead; Bertrand Russell; Gottfried Wilhelm Leibiniz; David Hume; Immanuel Kant; Willard van Orman Quine; Ernest Nagel; Noam Chomsky; Ludwig Wittgenstein e; Rudolf Carnap.

Se adotada a separação didática de Buckingham et al. (2016) que divide teorias e filósofos em contextos filosóficos, se percebe um amplo conhecimento de Taube sobre a história da filosofia. De 1500 a 1750, período identificado como ‘A Renascença e a Idade da Razão', se tem o trabalho de Leibniz, filósofo matemático e bibliotecário alemão, criador do cálculo que aperfeiçoa o código binário utilizado no desenvolvimento dos computadores, de abordagem racionalista. Pouco tempo depois, na 'Era da Revolução', de 1750 a 1900, Hume com sua abordagem empirista e Kant, com a abordagem do idealismo transcendental, também se destacam na Filosofia e aparecem na obra de Taube (Buckingham et al., 2016).

Neste caso, uma vez que Taube sinaliza uma concordância com o discurso de Leibniz e discorda de Hume, demonstra um conhecimento de duas vertentes clássicas da Filosofia: racionalismo e empirismo. Em linhas gerais, o racionalista se utiliza da razão para determinar crenças ou técnicas em um determinado campo enquanto que, o empirista, identifica na experiência o seu critério de verdade (Abbagnano, 2012).

Ainda na 'Era da Revolução' Whitehead, filósofo, lógico e matemático, desenvolve, na metafísica e na filosofia da ciência, a filosofia do processo. Para Buckingham et al. (2016: 336), a filosofia do processo era "baseada na sua convicção de que as categorias filosóficas tradicionais eram inadequadas para lidar com as interações entre matéria, espaço e tempo, e que 'o órgão vivo, ou experiência, é o corpo vivo como um todo', e não apenas o cérebro”. Ou seja, tem interesse em analisar o mundo real e aquilo que permite que o ser descreva e entenda a realidade de forma abrangente.

Whitehead influencia vários filósofos da primeira metade do Século XX, entre eles Russell, que é coautor da obra Principia Mathematica e que trabalha 
na vertente da Filosofia Analítica, assim como Quine. Este, de acordo com Buckingham et al. (2016), conhece Russell e estuda com Whitehead, o que demonstra uma consistência teórica nos escritos de Taube e reforça a proximidade do autor com a tal vertente filosófica.

O trabalho de Taube também toma por base as concepções do Positivismo Lógico. Neste sentido, os nomes citados por Taube, considerados entusiastas desta abordagem, são Carnap e Nagel. Portanto, a soma de todos estes autores sinaliza uma construção epistemológica que fundamenta a contribuição e o posicionamento analítico de Taube a partir da discussão do Positivismo Lógico e da Filosofia Analítica.

Nas discussões específicas da Biblioteconomia e Ciência da Informação, Taube se destaca ao discutir Biblioteconomia e Documentação, especialmente os conflitos entre os defensores de uma ou de oura área. Em termos epistemológicos, pode-se dizer que esta questão está conectada ao contexto de mudanças do objeto epistêmico destas disciplinas: a informação e o documento.

Com a Guerra Fria, Araújo (2018) destaca que a informação passa a ser considerada um recurso de produtividade, onde os cientistas necessitam ter acesso a diversos conteúdos informacionais de forma rápida e precisa. Neste sentido, a informação não está vinculada obrigatoriamente a um suporte físico e, por isso, assume a definição de um 'registro de conhecimento'.

Essa concepção trata a informação como fenômeno que se ramifica em tipos distintos de suportes. Assim, os materiais bibliográficos se constituem um tipo de registro de conhecimento, mas não mais o único, uma vez que outros registros também armazenam informações. Conforme apontam Cunha e Cavalcanti (2008: 201), a informação passa a ser considerada como um "registro de conhecimento para utilização posterior", onde é possível criá-la, armazená-la, recuperá-la e copiá-la, a fim de possibilitar sua disseminação. Uma concepção bem diferente do que defendia, até então, a Biblioteconomia, Documentação e a própria Filosofia.

Wagner Jr. (1960) afirma que a informação é a soma das relações entre termos em uma quantidade lógica. Ao comentar a Teoria da Informação, o autor explica que essa vertente estuda os métodos da transferência de sinais, aquilo que se entente acontecer entre o emissor e receptor. Nesse caso, o conceito de informação não se aparta do ato e das formas de comunicação.

Nessa seara, Taube (1961) comenta a escolha do termo 'informação' utilizado na teoria de Shannon. Para ele, a noção de informação discutida em Shannon não se aproxima da ideia de 'ser informado', pois está vinculada à questão fisicista da comunicação. Ademais, afirma que concorda com a escolha do autor pelo termo, e acredita que a catalogação e o processamento de dados realizados pela Biblioteconomia é, de certa forma, uma aplicação desta teoria. 
Para Slamecka e Taube (1964), a preocupação com o significado e a verdade da informação fica à cargo da Filosofia enquanto que Lógica, Matemática e Linguística, se preocupam com as questões estruturais e físicas da informação, uma visão que é refletida nos próprios textos de Taube. Afinal, sua discussão sobre a verdade das proposições se dá no âmbito filosófico, enquanto que os artigos voltados à aplicabilidade de suas teorias são publicados junto à Biblioteconomia.

Com isso, os autores colocam a informação como objeto central ao dizer que "nossa família é a informação" (Slamecka e Taube, 1964: 358. Tradução nossa), e afirmam que é preciso romper com a prática de buscar soluções na literatura de forma individual e específica para atender às questões da organização da informação. Essa postura de Taube faz com que o autor adentre num dos aspectos epistemológicos mais sensíveis ao que se constituiria como Ciência da Informação, que é o próprio objeto epistêmico da área. Isso porque, compreender a informação como conhecimento registrado foge às características da 'sacralidade' do documento, tanto no âmbito da Biblioteconomia quanto da Documentação.

Em síntese, com base nas afirmações de Taube (1941; 1952), é possível dizer que: documento é todo o conhecimento registrado independente de seu suporte; documentação é o conjunto de técnicas de armazenamento e recuperação da informação; Documentação é a área que abarca técnicas de publicações científicas e tecnológicas (documentação), da biblioteconomia especial (por conta de materiais e usuários especiais), e da biblioteconomia tradicional (no que tange à organização da informação e do conhecimento). Neste sentido é preciso destacar que, embora os conceitos de "informação" e "documento" sejam distintos para a área, é perceptível que Taube entende por "documento" aquilo que registra a "informação", sem distinção de suporte, formato e tipologia. Com isso, é possível aproximar tais definições com a compreensão atual da Ciência da Informação que, a partir de seu complexo objeto de estudo que é o fenômeno da informação, reúne diferentes disciplinas para estudar este objeto de maneira interdisciplinar.

Slamecka e Taube dizem que, esta definição da Biblioteconomia a partir da perspectiva profissional, contribui para que os serviços da área sofram pressões internas e externas devido aos avanços na organização e tratamento da informação, conforme demandas da sociedade. Os autores defendem que o fundamento social da Biblioteconomia está em oferecer um serviço à sociedade, serviço este que não cria conhecimentos novos, apenas faz a mediação deste conhecimento visando facilitar o processo de comunicação (Slamecka e Taube, 1964). 
Neste sentido, Taube utiliza a documentação para justificar este fundamento social que embasa a atividade técnica da área. $\mathrm{O}$ autor deixa explícito que a preocupação profissional vem do campo da documentação e recuperação da informação e que, mesmo com o envolvimento de bibliotecários, esta preocupação também é marcada pelo envolvimento de engenheiros, químicos e especialistas em computação que respeitam a tradição da biblioteconomia tradicional, mas que pensam em novos métodos de organização da informação para atender estas demandas (Taube, 1961).

É pertinente destacar que quando a documentação chega aos EUA, entre os anos de 1948 e 1949 duas disciplinas sobre tal temática são ministradas em instituições renomadas na área da Biblioteconomia: a Western Reserve University e a University of Chicago. Na Western Reserve, a disciplina foi ministrada por Helen Focke sob o nome de Documentação enquanto que, no caso da Graduate Library School da University of Chicago, Margaret Egan a ministra sob o nome de Organização Bibliográfica (Shera e Cleveland, 1977).

'Organização Bibliográfica' é o termo adotado pelos membros da Escola de Chicago e que, como afirmam Cunha e Cavalcanti (2008: 271), define "princípios e normas que se destinam a relacionar, de modo permanente, todos os documentos publicados, bem como a tornar acessíveis esses mesmos documentos". Definição esta que se aproxima do conceito de 'Documentação’ exposto em Wagner Jr. (1960), na proposta de dicionário de termos para a área em questão.

Ademais, Herner (1984) comenta a publicação de uma obra chamada Bibliographic Organization, em 1951, sob edição de Jesse Shera e Margaret Egan, onde trata sobre as tendências de indexação e classificação, além de discutir formas de publicação e pesquisa. No livro, o autor destaca que há textos tanto dos adeptos da biblioteconomia tradicional como daqueles que estavam na 'nova onda' de pesquisa científica e tecnológica, a exemplo de Mortimer Taube.

Shera também é reconhecido por Taube, mas ao contrário da literatura científica que o prestigia, ao lado de Egan, pela criação da Epistemologia Social (Shera, 1977), seu reconhecimento para Taube se dá a partir de sua vertente tecnicista. Nas palavras de Taube (1953), Shera foi um dos expoentes de destaque no que tange ao desenvolvimento da classificação bibliográfica. Shera é mencionado por Taube por suas pesquisas técnicas, como fundamentação para seus artigos, como o publicado em parceria com Vladimir Slamecka, intitulado "Theoretical principles of information organization in librarianship" (Slamecka e Taube, 1964).

Isto é reflexo das perspectivas diferentes que Taube e Shera possuem quanto à cientificidade da Biblioteconomia. Afinal, o movimento intelectual 
da Escola de Chicago acredita neste caráter científico, pautado numa epistemologia que sustenta a Biblioteconomia não somente como uma atividade prática. Enquanto que, para Taube, a Biblioteconomia é uma profissão aplicada, sem discussões que a sustentem em um status científico

Em 1964, Taube afirma que a tecnologia da informação que começa a integrar o contexto biblioteconômico também não pode ser vista como uma atividade científica. Inclusive, o autor esclarece que a Biblioteconomia deve se juntar à tecnologia da informação, pela semelhança prática de suas atividades, já que ambas se desenvolvem primeiro no escopo da prática, e só posteriormente é que se pensa sobre suas bases teóricas (Taube, 1964).

Por isso, Slamecka e Taube (1964) especificam duas vertentes de discussão que recaem sobre o debate da Biblioteconomia: o conteúdo intelectual e as habilidades práticas da área. Para eles, no conteúdo intelectual está presente no acúmulo de teorias, proposições e hipóteses utilizadas como os princípios norteadores da área. Os autores não entendem estes princípios como uma filosofia da Biblioteconomia, mas assumem que, dependendo da interpretação destes conceitos, estes termos são usados como sinônimos.

O segundo ponto discutido pelos autores é o que eles chamam de 'habilidades'. Neste sentido, o debate permeia os serviços prestados nas bibliotecas, os objetivos destes serviços e a função da profissão (Slamecka e Taube, 1964). Ou seja, questões próximas do que hoje se identificam como as competências do bibliotecário.

É perceptível que a Biblioteconomia vive um momento de afirmação de seu papel científico frente aos pares da área, principalmente quando se tem a publicação original da Epistemologia Social (Shera, 1977), em 1961. Ao mesmo tempo, em 1961 e em 1964, Taube assume, em suas publicações, um posicionamento contrário ao de Shera e dos demais membros da Escola de Chicago, uma vez que define a Biblioteconomia como uma atividade profissional.

Aqui, temos dois posicionamentos epistemológicos sobre a Biblioteconomia. De um lado, com a Escola de Chicago, uma definição de que a área tem condições de ser considerada uma ciência por meio da defesa epistemológica fundamentada no Pragmatismo de Dewey, exposta e aprofundada em Vieira e Karpinski (2020). E, por outro lado, profissionais que, neste caso, identificam-se com a vertente prática da documentação nos EUA que assumem a Biblioteconomia como uma disciplina aplicada, própria do fazer profissional, sem a obrigação de criar novos conhecimentos científicos justamente por não ser uma área científica.

Pela forma que Slamecka e Taube (1964) propõe duas vertentes de discussão na Biblioteconomia, é possível identificar que a crítica à utilização das teorias como uma filosofia da Biblioteconomia é um posicionamento contrário 
ao movimento que tenta consolidar a área como um campo científico nos EUA. Ao se deter às pesquisas de caráter técnico voltadas aos serviços prestados nas bibliotecas, Taube desenvolve o Sistema Unitermo, utilizando-se das práticas da documentação. Dessa forma, pode-se dizer que seu trabalho reflete o viés epistemológico pautado no conceito de informação que transita e/ou do caráter teórico-prático das atividades.

Criticar a ciência e, principalmente, enfrentar a secular Biblioteconomia não é algo que passa despercebido pela trajetória de Taube. Sua aproximação com engenheiros, matemáticos, linguistas e lógicos e seu relativo distanciamento teórico de outros profissionais renomados da área a exemplo de Jesse Shera é reflexo de sua crença em uma Biblioteconomia profissional, de caráter prático que pode servir como meio de aplicação de técnicas da documentação e da tecnologia da informação, e que se une a estas outras disciplinas por meio da informação.

Taube morre em 1965 e não acompanha os desdobramentos da Ciência da Informação, mas é possível aproximá-lo do conceito elaborado por Borko (1968), que identifica esta nova área como a responsável por investigar as propriedades e comportamento de todo o fluxo que envolve a informação. Ademais, a definição de Saracevic (1996) também contempla as percepções de Taube, afinal, afirma que a área é uma ciência, que abarca questões da prática profissional que busca resolver problemas da comunicação.

Portanto, este posicionamento de Mortimer Taube condiz com a afirmação de Rieder (2020) de que ele mesmo se considera um rebelde por invadir o Santo Graal das práticas biblioteconômicas com propostas radicais para a época. E demonstra, também, um discurso coerente em sua produção científica que une, pela informação, a Biblioteconomia e documentação, com discussões oriundas da lógica-matemática e da informática.

A produção de Taube e a citação de filósofos clássicos demonstram que o debate proposto pelo autor é profundo e consciente. Isto porque, Taube se utiliza de autores que discorda com o objetivo de ter argumentos que sustentem seu posicionamento. Outra questão a ser observada é que Taube reconhece teorias mesmo de autores que não concorda integralmente, como Chomsky e Locke, o que pode ser considerado reflexo de uma maturidade acadêmica e teórica.

Percebe-se que desde o momento que recém finaliza seus estudos na Filosofia, por volta de 1936 e 1937, Taube se mantém no escopo epistemológico ao longo de toda a sua carreira. Isso se percebe, especialmente, pela equilibrada produção científica entre os anos de 1955 e 1965 envolvendo estudos filosóficos e epistemológicos, mesmo nos textos vinculados às pesquisas da Documentation Incorporated. Esta discussão é epistemológica na medida 
em que submete a prática científica a uma reflexão nos termos de Japiassu (1977). Isto porque, para este autor, o estudo reflexivo do saber e o debate acerca de sua formação, desenvolvimento e funcionamento configuram os estudos epistemológicos.

Retomando o exposto por Cupani (2017), a epistemologia se preocupa de forma reflexiva sobre os saberes que produz. E, neste sentido, questiona-se acerca da consistência deste saber, sobre o conhecimento científico e o não científico (que o autor chama de vulgar), sobre o significado da utilização deste saber como, por exemplo, a tecnologia, e sobre a criação de novos saberes e/ ou mera repetição de um discurso entre seus pares. Por isso é possível afirmar que Taube propõe uma discussão epistemológica em sua área de atuação.

Tal conclusão toma por base sua reflexão a partir da informação que, posteriormente, se configura como um campo singular que aqui se identifica como Ciência da Informação. Assim, Taube se situa no campo epistemológico desta ciência uma vez que seus questionamentos refletem questões da Biblioteconomia e documentação, permeadas/retroalimentadas pela informação.

Nesse sentido, considerando a classificação proposta por Japiassu (1977), é possível identificar, no percurso epistemológico de Taube, uma aproximação com a Epistemologia Crítica. Isso porque, de acordo com Japiassu (1977), a Epistemologia Crítica se desenvolve a partir da reflexão dos cientistas sobre a própria ciência, por meio de uma reflexão histórica e um posicionamento que os faz indagar sobre o significado de sua prática científica.

Ao longo da trajetória de Taube, se verifica que seus posicionamentos e defesas são consonantes à consciência do poder científico em lançar teorias que, quando infundadas, se afastam das demandas da sociedade. Soma-se ainda a questão da falta de conhecimento histórico levantada por Taube para embasar suas críticas à ciência e sua defesa contra o 'endeusamento' da prática científica que, ao seu ver, deve dialogar com instituições governamentais ou da iniciativa privada desde que este diálogo seja frutífero tanto para as necessidades de sua época quanto para o próprio desenvolvimento da área em questão.

\section{ConsideraÇões finais}

Entende-se que a Ciência da Informação pode ter sua epistemologia discutida sob a perspectiva específica, uma vez que se propõe a reflexão em um determinado campo do saber científico, bem definido, detalhado e investigado com proximidade. Portanto, ao se debruçar sobre a história e discussão epistemológica da Ciência da Informação e os conflitos entre Biblioteconomia 
e Documentação é inevitável não encontrar nomes conhecidos como os de Julius Otto Kaiser, Jesse Hauk Shera, Conrad Gesner, Gabriel Naudé, Margaret Elizabeth Egan e Suzanne Briet.

Todavia, se entende que a pesquisa teórica pode se debruçar sobre nomes "marginais" que pouco são discutidos pela área, com vistas a investigar outras perspectivas influentes no processo de constituição da então Ciência da Informação. Neste artigo, portanto, a escolha por problematizar os construtos teóricos de Mortimer Taube serve como ponto de partida para a discussão das perspectivas epistemológicas identificadas neste autor que também participa da constituição da área por volta da década de 1950 e 1960.

Finalizadas estas considerações, assume-se que a contribuição técnico-científica de Taube e o posicionamento do autor frente algumas discussões como a cientificidade da Biblioteconomia, a chegada e demanda da documentação e recuperação da informação, o uso de conceitos vindos da Filosofia para embasar suas discussões teóricas e epistemológicas o colocam numa posição relevante na história da Ciência da Informação. Apesar de Taube não se considerar um cientista da informação, defende-se que as relações teórico-práticas que ele produz em sua bibliografia, os posicionamentos filosóficos que embasam sua atuação profissional e a forma como ele concebe a informação e o documento, o inserem entre os "grandes" precursores da Biblioteconomia e Ciência da Informação estadunidense.

Portanto, conclui-se que Taube se utiliza, em alguns aspectos, das contribuições do Positivismo Lógico e da Filosofia Analítica para construir suas discussões epistemológicas. Em momentos se aproxima, em outros se distancia, fazendo uso dos conceitos e críticas destas vertentes para embasar sua proposta teórico-prática. Percebe-se que estas bases filosóficas influenciam a própria Documentation Incorporated, especialmente no que tange às questões da linguagem.

Já as análises sobre o posicionamento epistemológico de Taube frente à Biblioteconomia e à documentação, possibilitam aproximá-lo à Epistemologia Crítica. Isto porque o autor demonstra, em diversos momentos de sua contribuição bibliográfica, a consciência do poder do discurso científico na promoção de teorias que, quando infundadas, geram impactos negativos à sociedade.

Acredita-se, por fim, que os resultados oriundos deste estudo beneficiam os pesquisadores envolvidos com os estudos históricos e epistemológicos da Ciência da Informação, por enriquecer a produção científica nacional acerca do tema, além de propiciar novos debates. Ademais, os resultados apresentados neste artigo colocam o nome de Mortimer Taube como o nome de mais um bibliotecário de destaque na história da área, ao lado de nomes como o de Shera que, dentro de sua perspectiva, discute e promove reflexões sobre o que hoje está institucionalizado como Ciência da Informação. 
À Coordenação de Aperfeiçoamento de Pessoal de Nível Superior (CAPES - BRASIL), pela concessão da bolsa de Demanda Social à autora Keitty Rodrigues Vieira, o que permitiu a realização do Doutorado sob regime de dedicação exclusiva.

À Susan Schwelling e Tali Schwelling, filha e bisneta de Mortimer Taube, que compartilharam informações importantes para a construção de tal pesquisa.

\section{REFERÊNCIAS}

Abbagnano, Nicola. 2012. Dicionário de Filosofia. 6a. ed. São Paulo: Editora WMF Martins Fontes.

Aguiar, Niliane Cunha de. 2014. "Tríades conceituais na epistemologia da Ciência da Informação". Ciência da Informação em Revista 1 (1): 4-11. https://doaj.org/article/2f3c4657131d431783f9f2e16b50ddd1

Araújo, Carlos Alberto Ávila. 2018. O que éCiência da Informação. Belo Horizonte: KMA.

Ávila, Rodrigo Fortes de, Maria Teresa Navarro de Britto Matos, e Miguel Ángel Rendón-Rojas. 2021. "Teorizar la teoría: un debate sobre la independencia epistemológica archivística". Investigación Bibliotecológica: archivonomía, bibliotecología e información 35 (86): 13-28. https://doi.org/10.22201/iibi.24488321xe.2021.86.58228

Azevedo, Marco Antônio de. 2004. "Informação e interpretação: uma leitura teórico metodológica". Perspectivas em Ciência da Informação 9 (2): 122-133. http://portaldeperiodicos.eci.ufmg.br/index.php/pci/article/view/354/163

Borko, Harold. 1968. "Information Science: What is it?" American Documentation $19(1): 3-5$. https://goo.gl/YpU9JS

Buckingham, Will, Douglas Burnham, Clive Hill, John Marenbon, e Marcus Weeks, col. 2016. O livro da filosofia. São Paulo: Globo.

Cunha, Ivan Ferreira da. 2012. "Rudolf Carnap e o pragmatismo americano: ferramentas para a filosofia da Ciência". Tese de doutorado, Centro de Filosofia e Ciências Humanas, Programa de Pós-Graduação em Filosofia, Universidade Federal de Santa Catarina, Brasil. https://repositorio.ufsc.br/bitstream/handle/123456789/96211/301893.pdf?sequence $=1$ \&isAllowed $=\mathrm{y}$

Cunha, Murilo Bastos da e Cordélia R. Cavalcanti. 2008. Dicionário de biblioteconomia e arquivologia. Brasília, DF: Briquet de Lemos, Livros.

Cupani, Alberto. 2017. Filosofia da tecnologia: um convite. 3a. ed. Florianópolis: Ed. Da UFSC.

Documentation Incorporated. 1953. Installation manual for the Uniterm System of coordinate indexing. Dayton, Ohio: Document Service Center, The Armed Services Technical Information Agency.

Dutra, Luiz Henrique de Araújo. 2010. Introdução à epistemologia. São Paulo: Ed. UNESP.

Fonseca, Edson Nery da. 2007. Introdução a biblioteconomia. 2a. ed. Manuais de estudo. Brasília, DF: Briquet de Lemos. 
Francelin, Marivalde Moacir. 2018. "Epistemologia da Ciência da Informação: evolução da pesquisa e suas bases referenciais". Perspectivas em Ciência da Informação 23 (3): 89-103. https://doi.org/10.1590/1981-5344/3135

Gull, Cloyd Dake. 1987. "Historical note: Information Science and Technology: from coordinate indexing to the global brain". Journal of the America Society for Information Science 38 (5): 338-366.

https://doi.org/10.1002/(SICI)1097-4571(198709)38:5<338::AID-ASI4>3.0.CO;2-1

Herner, Saul. 1984. "Brief history of Information Science". Journal of the American Society for Information Science 35 (3): 157-163.

https://doi.org/10.1002/asi.4630350308

Hjørland, Birger. 2002. "Epistemology and the socio-cognitive perspective in Information Science". Journal of the American Society for Information Science and Technology 53 (4): 257-270.

https://doi.org/10.1002/asi.10042

Japiassu, Hilton. 1977. Introdução ao pensamento epistemológico. 2a. ed. Rio de Janeiro: Francisco Alves.

Jones, Robert M. e Mortimer Taube. 1961. "Notes on the Distinction between character recognition machines and perceiving machines". American Documentation 12 (4): 292-293.

https://doi.org/10.1002/asi.5090120409

Lira, Bruno Carneiro. 2014. O passo a passo do trabalho científico. 2a ed. Petrópolis, RJ: Vozes.

Lucca, Djuli Machado de e Elizete Vieira Vitorino. 2020. “Information Literacy and its epistemological roots of Information Science: a focus on the phenomenological approach". Perspectivas em Ciência da Informação 25(3): 22-48.

https://doi.org/10.1590/1981-5344/3317

Martínez-Ávila, Daniel e Tarcisio Zandonade. 2020. "Social Epistemology in Information Studies: a consolidation". Brazilian Journal of Information Research trends 14 (1): 7-36. https://doi.org/10.36311/1981-1640.2020.v14n1.02.p7

Minayo, Maria Cecília de Souza, Suely Ferreira Deslandes, e Romeu Gomes. 2013. Pesquisa social: teoria, método e criatividade. 33ra ed. Petrópolis: Vozes.

Rendón-Rojas, Miguel Ángel. 2008. "Ciencia bibliotecológica y de la información en el contexto de las ciencias sociales y humanas, epistemología, metodología e interdisciplina”. Investigación Bibliotecológica 22 (44): 65-76. http://www.scielo.org.mx/pdf/ib/v22n44/v22n44a4.pdf

Rieder, Bernhard. 2020. "From universal classification to a postcoordinate universe". Em Engines of order: a mechanology of algorithmic techniques, 145-198. Amsterdam, Holanda: Amsterdam University Press. https://www.jstor.org/stable/j.ctv12sdvf1.8

Righetto, Guilherme Goulart e Cezar Karpinski. 2021. "For a decolonial social epistemology". Transinformação 33: 1-14. https://doi.org/10.1590/2318-0889202133e200039

Saldanha, Gustavo. 2020. Ciência da Informação: crítica epistemológica e historiográfica. Rio de Janeiro: IBICT. https://ridi.ibict.br/bitstream/123456789/1101/1/SaldanhaGustavo_CI_CriticaEpistemologicaHistoriografica_2020a.pdf 
Sales, Rodrigo de. 2012. "A presença de Kaiser no Quadro Teórico do Tratamento Temático da Informação (TTI)”. Tese de Doutorado, Universidade Estadual Paulista Júlio de Mesquita Filho, Faculdade de Filosofia e Ciências de Marília, Brasil. http://hdl.handle.net/11449/103381

Saracevic, Tefko. 1996. "Ciência da informação: origem, evolução e relações”. Perspectivas em Ciência da Informação 1 (1): 41-62.

http://portaldeperiodicos.eci.ufmg.br/index.php/pci/article/view/235/22

Shannon, Claude W. e Warren Weaver. 1964. The mathematical theory of communication. University of Illinois Press.

https://pure.mpg.de/rest/items/item_2383164/component/file_2383163/content

Shera, Jesse Hauk. 1977. "Epistemologia social, semântica geral e biblioteconomia”. Ciência da Informação 6 (1):9-12.

http://revista.ibict.br/ciinf/article/view/92/92

Shera, Jesse Hauk e D. B. Cleveland. 1977. "Donald B. History and foundations of Information Science". Annual Review of Information Science and Technology (ARIST): 249-275.

Silva, Tiago José da e Isa Maria Freire, org. 2020. Epistemologia e historiografia na Ciência da Informação. João Pessoa: Editora UFPB.

http://www.editora.ufpb.br/sistema/press5/index.php/UFPB/catalog/ view/740/871/68-1

Slamecka, Vladimir e Mortimer Taube. 1964. "Theoretical principles of information organization in librarianship". The Library Quarterly 34 (4): 352-361. http://www.jstor.org/stable/4305501

Taube, Mortimer. 1941. "The Theory of Book Selection". College E Research Libraries 2 (3): 221-225. https://doi.org/10.5860/crl_02_03_221

Taube, Mortimer. 1952. "Special librarianship and documentation". American Documentation 3 (3): 166-167. https://doi.org/10.1002/asi.5090030311

Taube, Mortimer. 1953. "Review: A bibliographic classification, extended by systematic auxiliary schedules for composite specification and notation by Henry Evelyn Bliss". College E Research Libraries 14 (4): 453-455. https://doi.org/10.5860/crl_14_04_453

Taube, Mortimer. 1961. "Documentation, information retrieval, and other new techniques”. The Library Quarterly 31 (1): 90-103. http://www.jstor.org/stable/4305078

Taube, Mortimer. 1964. "The coming of age of information technology". Bulletin of the Medical Library Association 52 (1): 120-127. https://www.ncbi.nlm.nih.gov/pmc/articles/PMC198080/pdf/mlab00182-0133.pdf

Taube, Mortimer. 1967. Os computadores: mito das máquinas pensantes. Rio de Janeiro: O Cruzeiro.

Taube, Mortimer e Irma S. Wachtel. 1953. "The logical structure of coordinate indexing”. American Documentation 4 (2): 67-68. https://doi.org/10.1002/asi.5090040206

Vieira, Keitty Rodrigues e Cezar Karpinski. 2019. "The historical and epistemological relations between Librarianship and Information Science in the Brazilian scientific production”. Transinformação 31: 1-11. https://doi.org/10.1590/2318-0889201931e180043 
Vieira, Keitty Rodrigues e Cezar Karpinski. 2020. Escola de Chicago e Ciência da Informação: influências, aproximações e contribuições. Curitiba: Editora Appris Ltda.

Wagner Jr., Frank S. 1960. "A dictionary of Documentation terms". American Documentation 11 (2): 102-119.

https://doi.org/10.1002/asi.5090110204

Para citar este texto:

Vieira, Keitty Rodrigues e Cezar Karpinski. 2021. "Epistemologia na Ciência da Informação: a visão de Mortimer Taube”. Investigación Bibliotecológica: archivonomía, bibliotecología e información 35 (88): 185-206. http://dx.doi.org/10.22201/iibi.24488321xe.2021.88.58428 